\title{
Logística agroindustrial, transportes e exportações do complexo da soja no estado de Minas Gerais, Brasil
}

(4) Patrick Pereira de Jesus

Programa de Pós-Graduação em Geografia, Universidade Estadual de Montes Claros, Brasil. https://orcid.org/oooo-0003-2614-9906 / http://lattes.cnpq.br/8806132580025318

\author{
Luiz Andrei Gonçalves Pereira \\ Programa de Pós-Graduação em Geografia, Universidade Estadual de Montes Claros, Brasil. \\ https://orcid.org/oooo-0002-7857-6611 / http://lattes.cnpq.br/3157455126919220
}

Recibido: 15 de agosto de 2019. Aceptado: 11 de noviembre de 2019.

\section{Resumo}

As interações entre os diversos agentes econômicos que atuam no complexo da soja em diferentes espaços mundiais demandam redes e serviços de transportes e de comunicação/informação na operacionalização dos movimentos de mercadorias. $\mathrm{O}$ artigo tem como objetivo analisar a comercialização de produtos do complexo da soja, considerando a infraestrutura e os serviços interligados à logística de transportes na interação espacial dos fluxos das exportações desde a origem da produção em Minas Gerais até os destinos nos mercados internacionais, no período de 1997 a 2016. Os procedimentos metodológicos adotados foram a revisão de literatura e a coleta e análise de dados disponibilizados pelas instituições públicas brasileiras. O texto discutiu a organização das redes de circulação de mercadorias (material e imaterial) e as interações dos fluxos nos mercados internacionais, a logística e as novas configurações de competividade do território brasileiro e do mineiro na dinâmica da produção e da circulação de soja in natura e derivados. Os mercados asiáticos e europeus foram os maiores compradores de mercadorias do complexo da soja produzidas pelos agentes econômicos localizados em Minas Gerais, que tiveram o escoamento dos seus produtos concentrado no sistema portuário e no transporte marítimo internacional.

Palavras-chave: Logística agroindustrial. Transportes. Exportações. Complexo da soja. Minas Gerais. 


\title{
Agroindustrial logistics, transport and exports from the soy complex in the state of Minas Gerais, Brazil
}

\begin{abstract}
The interactions among the many economic agents within the soy complex in many international markets demand networks and transportation, communication/ information services to operationalize the merchandise movements. This paper aim is to analyze the commercialization of products from the soy complex, considering the infrastructure and services linked to transport logistics in the spatial articulation of transport logistics in the exportation process, since its productions in Minas Gerais until the reach of international markets, in the period between 1997 and 2016. The methodological procedure adopted was the text review and the collection and analysis of data provided by public Brazilian's institutions. The text has discussed the organization of material and immaterial merchandise network flow and the flow interaction in international markets, logistics and the new competitive organization in the Brazilian and the state territory in the production and movement of in natura soy and its derivatives. The Asian and European markets were the largest buyers of commodities from the soy complex, produced by economic agents in the state of Minas Gerais, who had most of their goods outflowing mainly through ports and international maritime transport.
\end{abstract}

Key words: Agroindustrial logistics. Transport. Exportation. Soy complex. State of Minas Gerais. Palabras clave: Logística agroindustrial. Transportes. Exportaciones. Complejo sojero. Estado de Minas Gerais.

\section{Introdução}

A comercialização de soja e derivados passou por diversas transformações em decorrência das demandas, do processo de modernização da agricultura e dos investimentos em mercados físicos e em mercados futuros. A integração e as interconexões entre os mercados, localizados em várias nacionalidades, por meio das redes de fluxos materiais (transportes) e imateriais (informações e serviços) propiciaram a expansão das atividades socioeconômicas, bem como a comercialização de produtos e de serviços nos mercados internacionais. Nesse contexto, a logística surgiu como um serviço muito importante nas etapas táticas e estratégicas de planejamento, de gestão e de controle dos sistemas de fluxos para ampliar a produção, a circulação e a comercialização de produtos agrícolas nos mercados globais, incluindo o complexo da soja.

Na logística, os transportes assumem um papel relevante na movimentação dos fluxos comercializados do complexo da soja que incorpora produtos como a soja em grãos (in natura) e produtos processados (farelo e óleo de soja) destinados aos mercados consumidores nacionais e internacionais. Desse modo, a eficácia e a eficiência da infraestrutura e dos serviços de transportes podem garantir uma melhor operacionalização da logística, na circulação de produtos do complexo da soja, do local de produção (fazendas, armazéns e indústrias de processamento) até os recintos alfandegados nacionais e os mercados globais.

O interesse pela temática surgiu a partir da curiosidade por estudar a especialização produtiva e as estratégias de negócios dos agentes econômicos brasileiros e estrangeiros, localizados geograficamente por meio de suas corporações no território mineiro, no segmento de commodities agrícolas, destacando-se o setor do complexo da soja. Dessa forma, o desenvolvimento de estudos geográficos permitiu explicar e/ou compreender a dinâmica espacial dos mercados consumidores e as suas demandas pelos produtos agroalimentares para a alimentação humana, de animais (complexo da carne) e pela 
geração de (agro)energia. Essas dinâmicas aplicadas ao complexo da soja desenvolveram a estrutura de comercialização em um cenário de volatilidade dos preços, considerando os momentos de alta ou de queda de preços, quando as corporações e os comerciantes criam as estratégias de interações espaciais para serem competitivos em mercados, os quais incorporam a infraestrutura e os serviços de transportes, de armazenagem e de comunicação na viabilização dos fluxos internacionais de mercadorias.

Diante das abordagens apresentadas, este trabalho propõe a seguinte problemática de estudo: como está organizada a logística de transportes na operacionalização dos fluxos de mercadorias exportadas do setor agroindustrial do complexo da soja no território mineiro? $\mathrm{O}$ artigo tem como objetivo analisar a comercialização de produtos do complexo da soja, considerando a infraestrutura e os serviços interligados à logística de transportes na interação espacial dos fluxos das exportações desde a origem da produção em Minas Gerais até os destinos nos mercados internacionais, no período de 1997 a 2016.

Nesta pesquisa, os procedimentos metodológicos adotados foram sistematizados em duas etapas; na primeira, desenvolveu-se a revisão de literatura com a finalidade de discutir as temáticas ligadas à logística agroindustrial das commodities agrícolas, a comercialização e as dinâmicas espaciais das exportações do complexo da soja. Desse modo, os principais autores que subsidiaram as abordagens no referencial teórico foram Ballou (1993), Cleps Junior (1998), Caixeta-Filho (2001), Novaes (2001), Castillo (2004), Castillo (2005), Castillo (2007), Garcia e Andrade (2007); Silva (2007), Malagolli e Ascanio (2007), Lourenço (2009), Pontes et al., (2009), Castillo e Frederico (2010), Caixeta-Filho (2010), Pereira (2010), Fajardo (2011), Silveira (2011), Frederico (2013), Medeiros (2014), Pereira (2015), Pereira e Hespanhol (2015), Lima (2018), dentre outros meios de informação.

Na segunda etapa, realizou-se a coleta de dados das fontes secundárias disponibilizados pelo Instituto Brasileiro de Geografia e Estatística - IBGE - e pela plataforma virtual AliceWeb, vinculada ao Ministério da Indústria, Comércio Exterior e Serviços - MDIC, uma vez que essas informações foram muito importantes para verificar a evolução histórica da estrutura produtiva da soja em grão e analisar a dinâmica das exportações do complexo da soja no Estado de Minas Gerais. Os dados da produção estadual e da municipal de soja em grão em Minas Gerais foram extraídos do Instituto Brasileiro de Geografia e Estatística - IBGE por meio dos Anuários Estatísticos do Brasil - AEB - e do Sistema IBGE de Recuperação Automática - SIDRA; já os dados das exportações do complexo da soja foram coletados da plataforma AliceWeb 2 (MDIC). Na organização desses dados, utilizou-se o software Excel, versão 2010, para elaboração de tabela e de gráfico que representam as informações da produção e da exportação do setor do complexo da soja, respectivamente.

O complexo da soja foi estruturado por meio do agrupamento de dados disponibilizados em categorias de soja in natura (grão) e seus derivados, seguindo uma padronização internacional de classificação dos produtos, denominada de Sistema Harmonizado SH4, que são os códigos: 1201 (Soja mesmo triturada), 1507 (óleo de soja) e 2304 (torta derivada de soja/farelo de soja); também da padronização da Nomenclatura Comum do Mercosul - NCM, com os códigos: 21031010 e 21031090 (molho de soja), 12081000 (Farinha de soja), e 35040020 (proteínas de soja em pó). Depois que se criou o setor do complexo da soja, utilizou-se o software ArcGis, versão 10.3, para confeccionar os mapas temáticos com a finalidade de representar a evolução histórica da produção de soja em grão por municípios e de espacializar os fluxos das exportações (soja e derivados) no Estado de Minas Gerais em valores financeiros e em quilogramas por recintos alfandegados (portos, aeroportos e pontos de fronteiras), por transportes internacionais e por mercados globais agrupados em blocos econômicos. 


\section{Logística e transportes do setor agroindustrial}

Os agentes econômicos, localizados nos mais diversos países, promovem a circulação de mercadorias e de informações por meio da infraestrutura e da prestação de serviços, incluindo os serviços logísticos. Para Pereira e Ferreira (2016), os fluxos de informações, por causa da ampliação de acesso a telecomunicações e à informática, permitiram uma comunicação rápida e instantânea pelos agentes econômicos em espaços intra e internacionais que transformam as estruturas e os usos das redes em um processo de circulação de pessoas, mercadorias e informações, bem como a produção e a reprodução do capital no espaço geográfico. As inter-relações socioeconômicas dinamizam as redes de transações comerciais nas quais articulam espacialmente a interconexão de fluxos pelos sistemas de transportes e pelas comunicações. Na produção e na reprodução do espaço geográfico por meio da dinâmica socioeconômica, as interações espaciais são definidas como:

[...] um amplo e complexo conjunto de deslocamentos de pessoas, mercadorias, capital e informação sobre o espaço geográfico. Podem apresentar maior ou menor intensidade, variar segundo a frequência de ocorrência e, conforme a distância e direção, caracterizar-se por diversos propósitos e se realizar através de diversos meios e velocidades (Corrêa, 2006: 279).

Nas interações espaciais, as redes de trocas, de transportes e de informações interligam física e virtualmente os diferentes mercados no atendimento das demandas por produtos e por serviços no comércio internacional. Na estrutura das redes comerciais, a logística tem como propósito oferecer serviços que estimulam as transações comerciais entre produtores, vendedores e compradores na dinâmica dos mercados, já que, após a conclusão da venda, torna-se necessária a operacionalização dos fluxos de bens e serviços (Pereira, 2015). Na perspectiva da logística empresarial, Ballou (1993) e Novaes (2001) abordam que a logística estabeleceu uma gama de serviços na viabilização das conexões organizacionais de formas direta e indireta para que os agentes econômicos pudessem enviar as mercadorias do local de origem até o local de destino - incluindo o serviço pós-venda - com a finalidade de atender a clientela.

As redes de serviços logísticos são estabelecidas pelas táticas e estratégias adotadas pelos agentes econômicos na integração dos diversos componentes da estrutura produtiva, tendo como foco a competividade por meio da otimização dos fluxos na cadeia de suprimentos e/ou de distribuição. No acirramento das disputas pelos mercados consumidores, as empresas adotam as estratégias e/ou mecanismos para concorrerem no mercado global, visto que a logística se pauta na qualidade, na segurança e no baixo custo dos serviços durante o deslocamento de bens destinados aos consumidores. Além disso, os compradores, produtores, fornecedores e prestadores de serviços dependem da logística para a organização de estoques, o cumprimento dos prazos de entregas, a eliminação de desperdícios e a diminuição das incertezas nos mercados (Ballou, 1993; Novaes, 2001). Os estudos da logística estão concentrados na administração, mas a ciência geográfica também passou a abordar essa temática, inclusive por meio da interdisciplinaridade, para a compreensão das dinâmicas dos fluxos de bens e serviços que atendem as demandas dos consumidores, das atividades produtivas e dos negócios no espaço geográfico.

$\mathrm{Na}$ Geografia, a logística ganhou visibilidade no segmento comercial ao associar as interações e as organizações socioespaciais dos serviços voltados para o planejamento à gestão e ao controle dos fluxos no atendimento das demandas dos negócios, uma vez que os serviços logísticos têm como suporte a gestão de transportes, de armazenagem e de informações (Silveira, 2011). Para Pereira (2015), o principal desafio da logística é promover a redução dos custos sem comprometer a qualidade das mercadorias e dos serviços prestados. A logística é: 
[...] o conjunto de processos, procedimentos e ações que visa organizar e otimizar o movimento de produtos, desde o fornecimento de insumos até o consumo final. Implica no acompanhamento do produto em seu movimento, gerenciamento de estoques, just-in-time/just-in-place, importação/exportação e outros serviços vinculados ao armazenamento, distribuição e agregação de valor aos fluxos materiais (certificação, embalagem, etiquetas etc.) (Castillo, 2004: 83-84).

Na dimensão espacial da logística, os serviços são organizados em redes para otimizar a articulação e a sincronização dos fluxos de mercadorias. Por isso, a logística deve ser pensada conforme as demandas do público que os empresários queiram atingir em um processo de planejamento e de gestão de fluxos atrelados ao tipo de mercado, seja ele nacional ou internacional (global). Na política de exportações, a logística nacional está centrada na prestação de serviços que permite a organicidade e o controle na viabilização de fluxos do local de produção até os recintos alfandegados, localizados em territórios nacionais (Pereira, 2015). No Brasil, os recintos alfandegados são os espaços delimitados pela autoridade aduaneira, nos quais destacam-se os portos, os aeroportos e os pontos de fronteiras alfandegados, com a finalidade de controlar a movimentação, a armazenagem e o despacho aduaneiro de mercadorias destinadas ou procedentes do exterior (Brasil, 2009).

Enquanto a logística internacional é caracterizada pelos serviços prestados na movimentação de mercadorias entre os recintos alfandegados localizados em países distintos, buscando atender os requisitos propostos pelos agentes econômicos importadores, localizados no exterior (Pereira, 2015). Dessa forma, David e Stewart (2010) afirmam que a logística internacional tem o papel de vencer as incertezas e as inseguranças relacionadas aos fluxos e à armazenagem de mercadorias, incluindo os fluxos de informações e os serviços burocráticos e/ou de documentações. No cenário dos negócios, a logística internacional incorpora o setor agroindustrial, inclusive o complexo da soja, buscando dinamizar a produção de matérias-primas e o processamento de produtos que são comercializados e escoados nacional e internacionalmente.

Na dinâmica dos setores agroindustriais, segundo Caixeta-Filho (2001 e 2010), a logística agroindustrial é um elemento-chave que engloba os serviços especializados das atividades e/ou dos segmentos da estrutura produtiva e de comercialização, que estão integrados ao gerenciamento da cadeia de suprimentos, focando na integração dos elos por meio das ações estratégicas adotadas pelos diversos agentes econômicos, pelos setores (agro)industriais e pelas redes de distribuição de produtos agroalimentares. A expansão das atividades agrícolas para as regiões brasileiras mais afastadas dos locais de consumo exige corredores de transportes que sejam responsáveis, principalmente, pela movimentação de mercadorias destinadas às exportações, incluindo as infraestruturas de escoamentos, de transbordos e de armazenagens de produtos.

No complexo agroindustrial de commodities agrícolas também destinadas as exportações, Lourenço (2009) classifica o uso da atividade logística integrada em três etapas: $1^{\text {a) }}$ a logística de suprimentos é responsável pelos fluxos de matéria-prima e de produtos até os setores de operação e de comercialização, uma vez que o objetivo maior é reduzir o tempo e os custos de produção; $2^{\mathrm{a}}$ ) a logística de operações de apoio à produção agropecuária incorpora todos os agentes econômicos que participam da cadeia produtiva, seja como fornecedores de insumos, de máquinas e de equipamentos, incluindo as indústrias de processamento, o setor de distribuição e de comercialização, bem como o consumidor final; $3^{\mathrm{a}}$ ) a logística de distribuição insere os segmentos de movimentação dos produtos agrícolas e/ou derivados por meio da armazenagem, do processamento, do ensacamento, dos serviços burocráticos e dos transportes, dentre outros.

Os sistemas agroindustriais dependem da logística na organização da infraestrutura e no escoamento dos fluxos de produtos destinados aos mercados globais. Na concepção de 
Leal e França (2011), a implantação das atividades capitalistas no espaço rural, processo conhecido como Revolução Verde, resultou na (re)organização dos espaços agrícolas, uma vez que esses tornaram-se complexos agroindustriais. Diante das transformações territoriais, a agricultura comercial é (re)estruturada com padrões de consumo capitalista, enquanto a agricultura de autoconsumo perde espaço para o agronegócio, transformando, assim, o modelo de produção adotado pelos agentes econômicos.

Nesse contexto, Lourenço (2009) pontua que o segmento agroindustrial brasileiro vem, ao longo dos anos, passando por modificações constantes na sua estrutura de produção e de comercialização. Os diversos agentes econômicos que compõem a estrutura do complexo agroindustrial otimizam a produção e o processamento, buscando de forma constante a redução dos custos de movimentação. A logística surgiu no segmento do agronegócio para impulsionar a produção e reduzir os custos relacionados às operações do complexo agroindustrial de commodities agrícolas. Nas operações das agroindústrias, o uso das atividades logísticas é indispensável para o comércio agroexportador, pois as empresas buscam cada vez mais participação no mercado internacional. Dentre as várias atividades logísticas, pontuam-se duas, a armazenagem e os transportes, que são consideradas importantes, pois, quando não operadas eficientemente, podem oferecer gargalos e comprometer os lucros das empresas.

No setor de commodities agrícolas, a armazenagem é uma atividade essencial para reduzir as perdas agrícolas, para manter a conservação do produto e para aguardar melhoras nos preços dos produtos na entressafra (Caixeta-Filho, 2010). Para Malagolli e Ascanio (2007), a armazenagem está interligada ao estoque em armazéns/silos de matérias-primas e de produtos processados de uma empresa. Ressalta-se serem os armazéns os espaços físicos responsáveis pela estocagem de produtos com a finalidade de esperar a sua distribuição nos mercados por meio da utilização dos meios de transportes.

A acessibilidade aos armazéns é estratégica na gestão dos estoques, no controle dos preços e no manejo da distribuição de produtos agroalimentares comercializados. Além da armazenagem, outro elemento relevante na logística agroindustrial é o transporte que operacionaliza a logística no processo de distribuição espacial dos produtos. Nas palavras de Caixeta-Filho (2001 e 2010), Castillo (2004), Lourenço (2009) e Pereira (2015), o transporte é um segmento importante a partir do sistema pós-colheita, uma vez que sem ele se torna impossível movimentar as commodities agrícolas em etapas do sistema de produção e de distribuição nos mercados. As demandas por transportes ocorrem, em primeiro lugar, com o escoamento dos grãos da propriedade rural até as cooperativas, os armazéns e/ou as indústrias de processamento; em segundo lugar, as commodities agrícolas são destinadas ao mercado de venda nacional e internacional; em terceiro lugar, as mercadorias agrícolas, sejam elas in natura ou processadas, seguem para os recintos alfandegados, consequentemente, para os mercados internacionais; e, em quarto lugar, as mercadorias são escoadas das empresas produtoras, fornecedoras, negociadoras e prestadoras de serviços até o consumidor final.

Na cadeia logística, todos os elos de serviços nos fluxos de mercadorias envolvem as interações entre as atividades primárias da logística, que são transportes, estoques/ armazenagem e processamento de pedidos (Ballou, 1993). Para Caixeta-Filho (2010) e Caixeta-Filho (2001), o transporte é de fundamental importância para a operacionalização da logística das atividades agroindustriais, uma vez que viabiliza o acesso e o escoamento da mercadoria materializada para os mercados consumidores. E o fato de os produtos agroindustriais terem baixo valor agregado, os preços dos fretes têm impactos diretos no preço final dos produtos agroalimentares, por isso, é necessário ter uma infraestrutura logística otimizada com foco na redução dos custos operacionais e na eficiência da operacionalização dos fluxos de bens e serviços nos mercados consumidores. 
Os fluxos de mercadorias do setor agroindustrial destinados ao mercado internacional estão intimamente ligados às interações dos sistemas intermodais de transportes e também aos terminais de armazenagem. Ao analisar as redes dos modais de transportes, conforme Pereira e Ferreira (2013), cada modalidade forma a sua rede específica, mas, quando juntam duas ou mais, tem-se uma rede de transporte intermodal mais complexa, que precisa ser interconectada pelos terminais de transportes. Nas redes de transportes são estabelecidas relações por meio de um conjunto de artérias formado pela ligação da infraestrutura viária (vias rodoviárias, ferroviárias, marítimas e aéreas) com os terminais de transportes (portos, aeroportos, armazéns etc.) com a finalidade de viabilizar a circulação de cargas no espaço geográfico nacional e no internacional.

A seletividade espacial expressa na infraestrutura, segundo Huertas (2015), dá-se por meio das funcionalidades, das polarizações e dos atributos que denotam, por um lado, a dissociação; e, por outro lado, a conectividade dos lugares, uma vez que essa seletividade ocorre por meio da densidade dos fixos e da intensidade, da qualidade e frequência dos fluxos que circulam pelas redes, principalmente de transporte. $\mathrm{Na}$ arena territorial, os agentes se posicionam de forma estratégica visto que existem maiores possibilidades de encontrar a oferta e o serviço de transporte para atender a capacidade de produção, de coleta, de armazenagem e de distribuição dos produtos.

No percurso do escoamento de produtos do complexo da soja das fazendas, dos armazéns ou das unidades processadoras até recintos alfandegados, os agentes econômicos com negócios no território brasileiro enfrentam diversos gargalos logísticos infraestruturais e institucionais. Eles são visíveis na precariedade da infraestrutura portuária, rodoviária e ferroviária; na burocracia para o desembaraço das mercadorias; nos congestionamentos em períodos do pico de safras nas regiões dos portos; e na baixa oferta de armazéns nas fazendas ou no seu entorno para estocagem da soja. As deficiências nas infraestruturas acabam forçando os empresários a vender, por preço mais baixo, a safra de soja em período de grande oferta nos mercados, uma vez que a capacidade de armazéns/silos não atende as demandas de armazenagem para aguardar a valorização desse produto no mercado, principalmente no período de entressafra (Pontes et al., 2009; Caixeta-Filho, 2010).

Os discursos dos players do agronegócio expõem que as deficiências da infraestrutura de transportes e da rede de armazenagem ao longo cadeia produtiva agroindustrial comprometem a competitividade por meio da elevação dos custos operacionais de produção e de distribuição de commodities agrícolas nos mercados. A observação de Castillo (2004, 2005 e 2007) é que não se podem desconsiderar os problemas de infraestrutura e de legislação dos sistemas de transportes, de armazenagem e de regimes aduaneiros voltados para a circulação de mercadorias e de commodities agrícolas destinadas aos mercados interno e externo. Mas as políticas estatais priorizaram os investimentos em infraestrutura (transportes, energia, telecomunicações e saneamento básico) em novas áreas produtoras de commodities agrícolas nos cerrados - do Centro-Oeste, Triângulo Mineiro, Oeste da Bahia, Sul do Maranhão e do Piauí - em conformidade com os interesses corporativos do setor privado. As políticas de privatizações e de concessões da infraestrutura e dos serviços públicos de transportes e de armazenagem tornaram-se negócios expressivos com a participação de um número reduzido de empresas privadas.

As grandes empresas do agronegócio, principalmente das empresas transnacionais do complexo da soja, fazem uso corporativo do território brasileiro para a produção de produtos primários e a comercialização de insumos, de commodities agrícolas e de serviços nos mercados interno e externo. Desse modo, os investimentos públicos e privados no sistema logístico, de transportes (rodoviário, ferroviário e hidroviário) e de comunicação (redes telemáticas de transmissão de dados) nos corredores estratégicos de integração nacional atendem também as exportações do complexo da soja. 
Porém, a centralização de capital em monoculturas, estimulada pelos investimentos em infraestrutura, pelos incentivos fiscais e pelos empréstimos subsidiados, tem contribuído com a "Guerra fiscal" que estrangula o pacto federativo. Essas medidas colocam em xeque a centralização da produção e da exportação de produtos primários como uma saída viável para inserção do Brasil nos mercados internacionais em detrimento dos interesses sociais (Castillo, 2004).

A competitividade brasileira no segmento agroexportador do complexo da soja é decorrente da modernização agrícola que transformou o espaço rural, a partir das décadas de 1960 e 1970, com o Estado sendo o principal financiador e articulador dos agentes responsáveis pela modernização da agricultura, sendo eles: agroindústrias, produtores, proprietários fundiários e tradings (Frederico, 2013; Castillo, 2004 e 2010). Para Frederico (2014), o Estado brasileiro subsidiou os produtores por meio de incentivos fiscais e de créditos, bem como estimulou a ocupação de novas fronteiras agrícolas, os investimentos biotecnológicos e a internacionalização do segmento agroindustrial. No setor agrícola, a Empresa Brasileira de Pesquisas Agropecuárias - EMBRAPA desenvolveu pesquisas para a difusão de várias espécies de soja adaptadas às regiões de cerrado, incorporando prestação de serviços de assistência técnica voltados para o manejo e para as correções de acidez do solo.

Nos argumentos de Castillo (2004) e Frederico (2010), a crise mundial estabelecida durante a década de 1970 repercutiu no Brasil, atingindo de forma direta o aparelho do Estado. Diante da crise fiscal, o Estado pouco a pouco deixou de ser o principal agente articulador e financiador do setor agrícola; nessa conjuntura, houve uma forte desaceleração no ritmo de expansão da fronteira agrícola. Em função da crise, a partir da década de 1990, o Estado promoveu novas políticas neoliberais, incluindo privatizações, concessões, abertura comercial, diminuição de subsídios, dentre outras. Assim, cada vez mais que a abertura comercial se intensificava, as empresas agroindustriais e tradings assumiam o controle gradativamente das atividades dos circuitos espaciais produtivos (processamento agroindustrial, armazenamento, transporte, vendas de sementes e fertilizantes, financiamento, comercialização e exportação). No contexto dos mercados de commodities agrícolas, na próxima seção, discutem-se a caracterização do território mineiro e a logística de transportes, responsável pelo escoamento das exportações do complexo da soja.

\section{Expansão das commodities agrícolas em Minas Gerais: logística de transportes e exportações do complexo da soja}

O Estado de Minas Gerais possui uma extensão territorial de 586.520,732 Km2, subdividido em 853 municípios, os quais abrigam uma população de 19.597 .330 habitantes e desenvolvem diversas atividades agropecuárias, extrativistas (mineração), industriais, comerciais/serviços. O território mineiro encontra-se localizado na região Sudeste do Brasil, delimitando com os estados de São Paulo, Rio de Janeiro, Espírito Santo, Distrito Federal, Goiás, Mato Grosso do Sul e Bahia (IBGE, 2010; IBGE, 2017). No processo de caracterização de Minas Gerais, Silva (2007) considera que a formação histórica contribuiu para a dinâmica socioeconômica estruturada em uma significativa base de recursos naturais que propiciou a integração inter-regional e transformou-se em um Estado industrializado e exportador.

A formulação de políticas públicas econômicas nos cenários estadual e federal tornou o Estado de Minas Gerais, principalmente a partir da década de 1970, um centro de atração de investimentos públicos e privados que impulsionaram a estruturação produtiva nos setores industrial e agropecuário (Garcia; Andrade, 2007). Ao discutir a 
distribuição espacial das atividades socioeconômicas ligadas à agricultura e à pecuária, Pereira e Hespanhol (2015) pontuam que o setor agropecuário tem uma maior concentração nas microrregiões do Triângulo Mineiro/Alto Parnaíba e do Sul de Minas. Considerando a dinâmica do setor agrícola comercial:

\begin{abstract}
No Triângulo Mineiro/Alto Parnaíba (sic) e Sul de Minas predomina o agronegócio, com destaque para as médias e grandes propriedades que direcionam a produção para o mercado externo, destacando-se a pecuária de corte e os cultivos de canade-açúcar e grãos (principalmente soja) no Triângulo e a cafeicultura na porção sudoeste, com intensa utilização do pacote tecnológico veiculado pela chamada "Revolução Verde" (Pereira; Hespanhol, 2015:53).
\end{abstract}

As atividades agrocomerciais desempenham um papel importante na economia mineira, principalmente nas mesorregiões de fronteiras agrícolas. Dessa forma, no setor agrícola, a expansão do complexo da soja está relacionada com a área de cultivo (soja em grão) e com as instalações de agroindústrias processadoras que demandam soja in natura para elaboração de seus produtos. Na década de 1970, segundo Cleps Junior (1998), o aumento da produção de soja ocorreu com a implementação de pesquisas que desenvolveram variedades de soja adaptadas ao cultivo em áreas de cerrado. Fatores como o baixo custo do preço da terra; a correção dos solos; os incentivos estatais fiscais; os financiamentos subsidiados para produção e para indústria de processamento; a melhoria da infraestrutura (transportes, armazenagens e comunicações) e a alta mecanização do processo produtivo com uso de insumos e de máquinas também contribuíram para a expansão da sojicultura em Minas Gerais.

Na década de 1980, a crise fiscal reduziu os incentivos estatais destinados ao setor do agronegócio, enquanto o capital privado ampliou a sua participação nas atividades agroindustriais, com destaque para as grandes corporações. As empresas do complexo da soja se especializaram na produção de soja em grão, de óleos vegetais e de rações (farelos) que são comercializados nos mercados brasileiros e internacionais. $\mathrm{Na}$ dinâmica da agroindústria em Minas Gerais, especialmente no Triângulo Mineiro, a partir da década de 1970/1980, as indústrias de fabricação de insumos (fertilizantes), de processamento de grãos e de atividades integradas à criação de animais para serem abatidos em frigorífico também foram incentivadas pelas ações estatais, expandiram o seus negócios e aumentaram a demanda por produtos do complexo da soja (Cleps Junior, 1998).

Nos mercados de matérias-primas do complexo da soja, a Figura 1 mostra a evolução histórica da estrutura produtiva da soja em grão, sendo que em 1952, a produção de soja no território mineiro apareceu nas estatísticas oficiais com a produção de $148(\mathrm{t})$; em 1960, a produção de soja chegou a $222(\mathrm{t})$, saltando para $1.806(\mathrm{t})$ em 1970; enquanto, em 1980, a produção de soja atingiu $289.542(\mathrm{t})$, crescendo para $748.794(\mathrm{t})$ em 1990, e chegando a 1.434.950 (t) em 2000. Em um processo de crescimento intenso, de 2000 para 2010, a produção de soja atingiu 2.871.219 (t) e, em 2016, chegou a 5.047.709 (t), que foi a maior produção em todo o período analisado. 


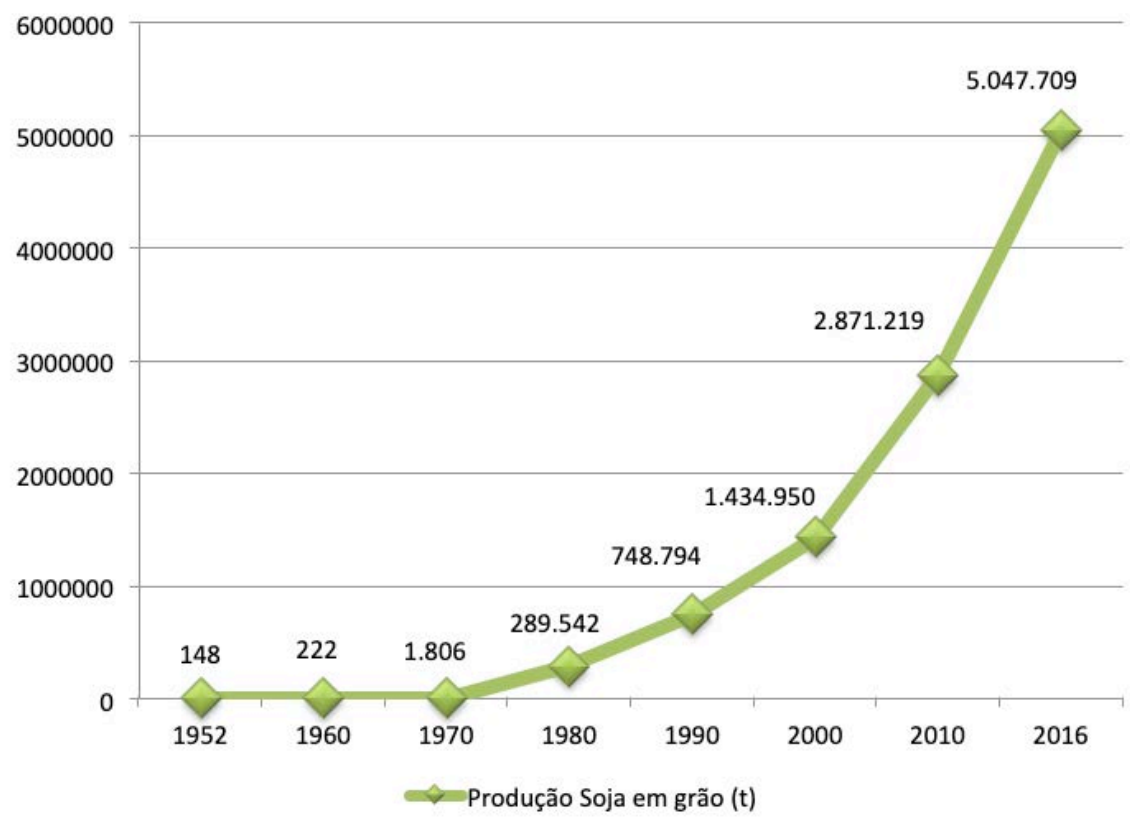

Figura 1. Evolução histórica da produção de soja em grão no Estado de Minas Gerais, período de 1952 a 2016 (toneladas). Fonte: Brasil, Instituto Brasileiro de Geografia e Estatística - IBGE, 1955; 1963; 1971; 1981; 1993; 2000; 2010; 2017. Org. Pereira, L. A. G., 2019.

O cenário de expansão da produção de soja em grãos no estado de Minas Gerais mostrou um crescimento mais acelerado, a partir da década de 1970/1980, em função da expansão da agricultura (agro)comercial incentivada pelas ações estatais, as quais atraíram o capital privado. A evolução da produção municipal de soja em grão no território mineiro, de 1974 a 2016, ocorreu nas mesorregiões do Triângulo Mineiro, Alto Paranaíba, Sul de Minas, Noroeste de Minas, Centro-Oeste de Minas, Central e Norte de Minas onde as atividades empresariais foram-se instalando, contribuindo, assim, para a intensificação produtiva da soja em grãos. Destacam-se, na produção de soja em grãos, os municípios de Araguari, Bonfinópolis de Minas, Perdizes, Buritis, Buritizeiro, Conceição das Alagoas, Coromandel, Formoso, Frutal, Guarda-Mor, Ibiá, Indianópolis, Ituiutaba, Monte Alegre de Minas, Monte Carmelo, Nova Ponte, Paracatu, Patos de Minas, Patrocínio, Prata, Presidente Olegário, Rio Paranaíba, Sacramento, Santa Juliana, Três Corações, Uberlândia, Uberaba, Unaí, dentre outros munícipes, conforme mostra a Figura 2. 


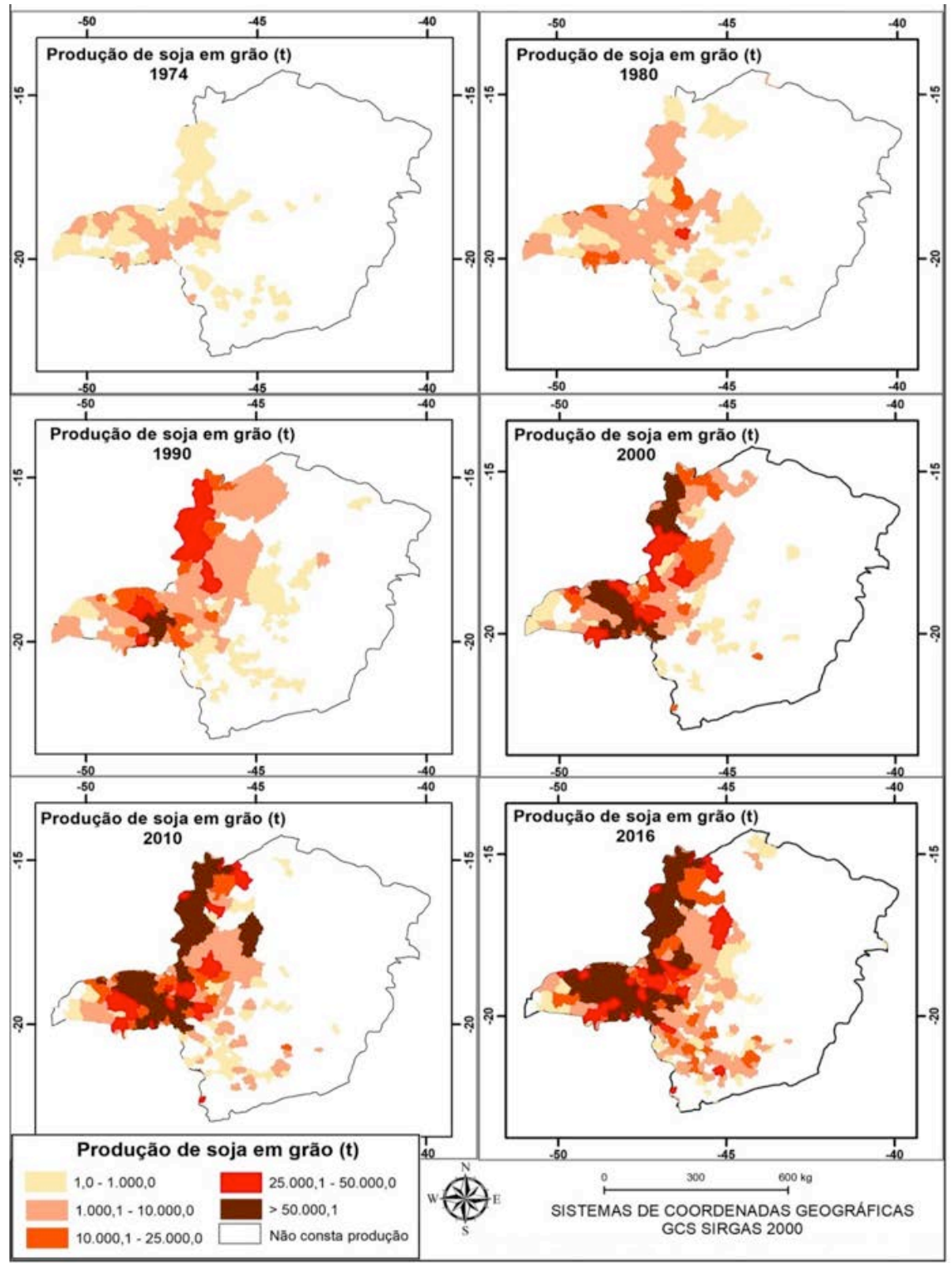

Figura 2. Minas Gerais: produção de soja em grão por municípios de 1974 a 2016 (toneladas). Fonte: IBGE, 2018; IBGE, 2019. Org. Pereira, L. A. G. 2019.

As interações espaciais da infraestrutura e dos fluxos reforçam a interconectividade entre os agentes transportadores e os agentes que atuam nos circuitos produtivos. A localização das atividades econômicas tem relação com a formação dos custos de fretes e com as condições de fluidez territorial que se estruturam a partir dos trechos privilegiados do transporte rodoviário e da acessibilidade dos agentes às ferrovias, às hidrovias, aos portos e aos aeroportos (Huertas, 2015). Na estruturação da cadeia produtiva e nas estratégias de comercialização de produtos do complexo da soja voltados para a exportação, a infraestrutura e os serviços de transportes têm o papel de interligar as regiões produtoras, os armazéns (silos), as unidades processadoras, os recintos alfandegados e os mercados globais.

A logística de transportes intraestadual que atende as demandas do setor agroindustrial mineiro, incluindo o complexo da soja, é constituída por rodovias pavimentadas de pistas simples e/ou duplas, dentre elas, destacam-se as BR 050; BR 365; BR 040; BR 262; BR 381; entre outras. Ressalta-se que, nas áreas rurais, a maioria das estradas não é 
pavimentada, o que causa muitos transtornos para as empresas e para os produtores do setor agrícola. No transporte intermodal, o território mineiro dispõe de três terminais intermodais, que são o Terminal Integrador de Pirapora, o de Araguari e o de Uberaba, que realizam as interconexões dos fluxos de produtos agrícolas transportados pelo modal rodoviário e pelo modal ferroviário. A rede ferroviária é operacionalizada por empresa privada, que é a Valor da Logística Integrada - VLI, que realiza a movimentação de cargas agrícolas até os portos (Porto de Tubarão e porto de Santos). Além da infraestrutura de transportes em Minas Gerais, existem também a redes de armazenagens de produtos do complexo da soja nas regiões agrícolas. Essas informações são visualizadas na Figura 3.

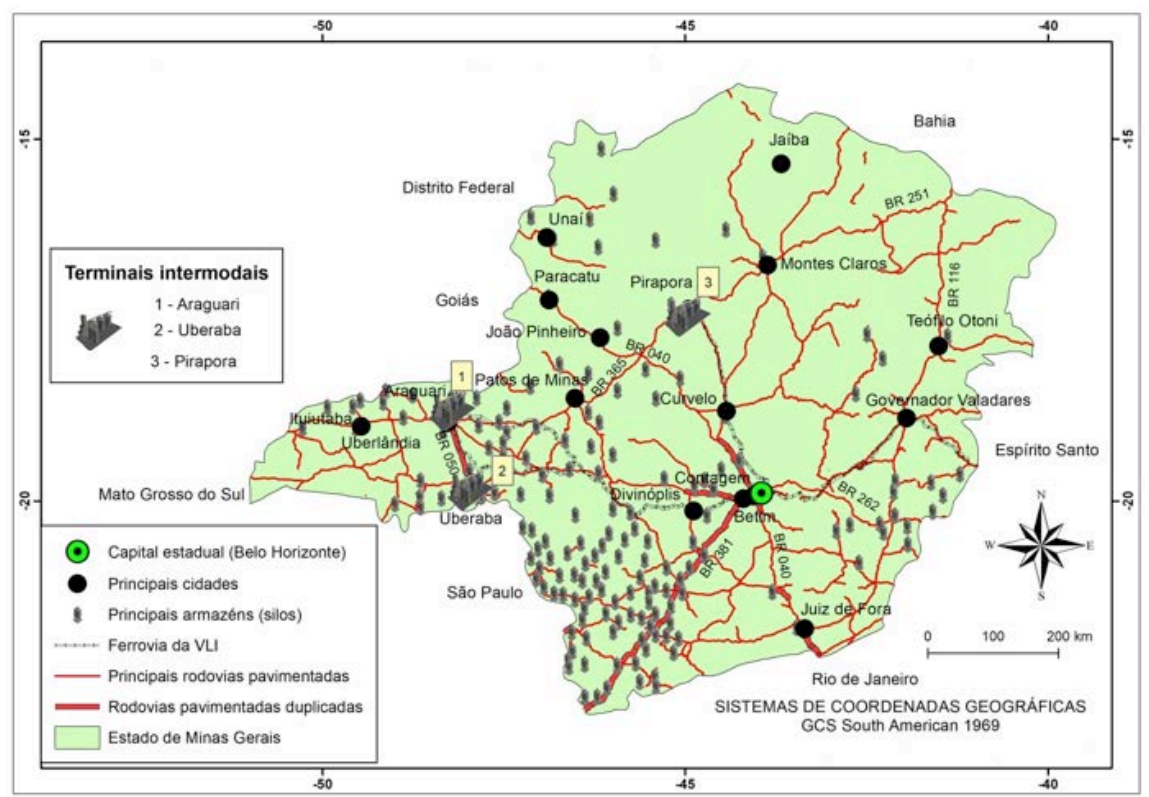

Figura 3. Estado de Minas Gerais: Infraestrutura de transportes e armazéns (silos) do setor agroindustrial. Fonte: Brasil - PNLT, 2010; IBGE, 2017. Org. Pereira, L. A. G., 2019.

No contexto da modernização econômica, observam-se os investimentos na expansão e na melhoria da infraestrutura de transportes, de energia e de comunicação nas áreas de fronteiras agrícolas. Ao discutir a organização da infraestrutura logística e de transporte intraestadual, torna-se necessário fazer uma representação da conexão da rede viária mineira com a brasileira, consequentemente, a sua integração e articulação com os recintos alfandegados aquaviários (portos), terrestres (pontos de fronteiras) e aeroviários (aeroportos), que são os principais nodos de interligação dos centros de produção do Brasil e de Minas Gerais aos mercados internacionais, conforme demonstra a Figura 4. 


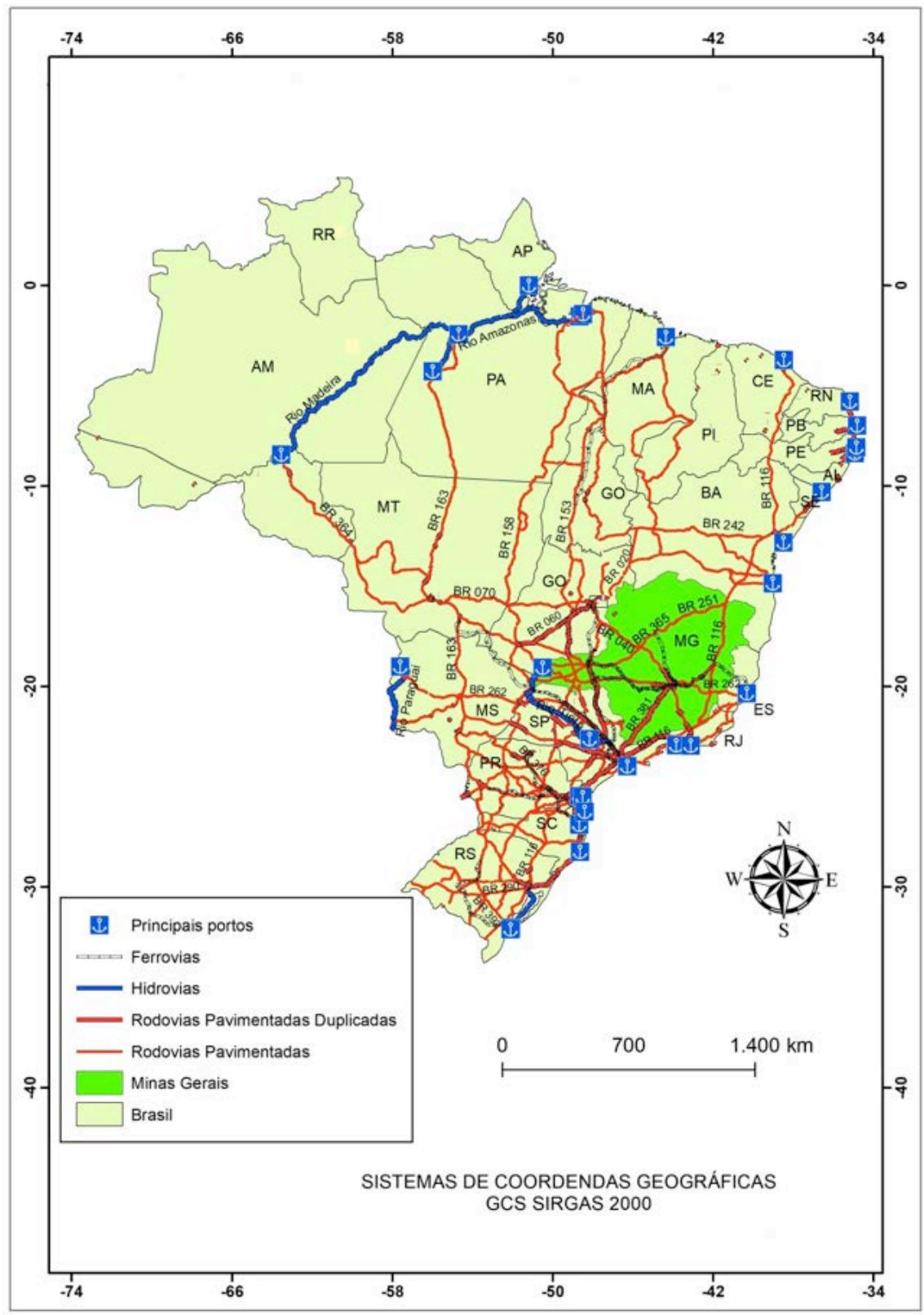

Figura 4. Infraestrutura de transportes: o Estado de Minas Gerais nas principais rotas de escoamento do complexo da soja no Brasil. Fonte: Brasil: Ministério dos Transportes, Portos e Aviação Civil, 2017. Org. Pereira, L. A. G., 2019.

No Estado de Minas Gerais, a soja em grão e seus derivados são escoados pelo uso da infraestrutura e dos serviços de transportes rodoviário, ferroviário e intermodal, que levam os produtos das regiões produtoras ou dos locais de armazenagem até os recintos alfandegados. Observa-se uma concentração do transporte do complexo da soja no modal rodoviário, que segue a mesma estrutura da política de transporte brasileira. Apesar da concentração dos produtos do complexo da soja na modalidade rodoviária, no território mineiro, a partir de 2009, ocorreu a expansão dos transportes intermodais, que realizam a integração dos fluxos entre o transporte rodoviário e o transporte ferroviário de commodities agrícolas. 
Nas exportações do complexo da soja, são utilizadas as infraestruturas de transportes nacionais e internacionais que dependem das interconexões de duas ou mais modalidades de transportes, principalmente nos fluxos intercontinentais, formando a matriz de transporte intermodal. Para Hoyle e Knowles (2001), a intermodalidade de transporte é caracterizada pela utilização de dois ou mais meios de transportes pelo transportador na interação espacial de unidade de carga, que envolve o remetente (quem envia) e o destinatário (quem recebe). O transportador - frota própria ou prestador de serviços - tem a função de fornecer um serviço contínuo para a circulação da carga, aproveitando as vantagens de cada matriz de transporte e a combinação deles como forma de reduzir os custos e aumentar a eficiência na prestação de serviços para a entrega do produto ao distribuir e/ou consumidor.

O complexo da soja exportador, localizado em Minas Gerais, também faz a utilização do transporte intermodal, tanto nas rotas do percurso nacional quanto nas rotas internacionais, que envolvem a origem e o destino dos fluxos. Na intermodalidade rodoferroviária, o transporte rodoviário leva os produtos agrícolas das regiões produtoras até os terminais integradores. Nesses terminais, os produtos são descarregados e são embarcados em trens cargueiros, que os levam até portos por onde saem as exportações. Nos terminais intermodais existem também a infraestrutura e os serviços de transbordos e de armazenagem de produtos agrícolas que podem ser utilizados pelos agentes econômicos. Em Minas Gerais, são três terminais integradores de transportes intermodais em operação, de Pirapora, de Araguari e de Uberaba, voltados para movimentação de cargas agrícolas.

Em 2009, foi inaugurado o Terminal Integrador de Pirapora que recebe cargas de soja e de milho das regiões produtoras de grãos de Minas Gerais, Goiás, Bahia, dentre outras. Ele está inserido no corredor de transporte denominado de "Centro-Leste", interligando especialmente as fronteiras agrícolas, o terminal de Pirapora e o complexo portuário de Vitória (Porto de Tubarão). Em 2012, foi inaugurado o Terminal Integrador de Araguari, que recebe cargas de produtos agrícolas - soja, milho e farelo de soja - de regiões de Minas Gerais, Goiás, Mato Grosso etc., que circulam pelo corredor de transporte "Centro-Leste", incluindo regiões produtoras e Araguari com destino à região portuária de Vitória (Porto de Tubarão). Esse terminal integrador recebe os fertilizantes do mercado nacional e também do mercado internacional que são destinados às regiões agrícolas. Em 2016, foi inaugurado o Terminal Integrador de Uberaba para receber cargas agrícolas (soja, milho e farelo de soja) de regiões agrícolas de Minas Gerais, de Goiás e do Mato Grosso, dentre outras. Ele está incorporado ao corredor de transporte Centro-Sudeste, que promove a interconexão entre as áreas produtoras e Uberaba à região portuária de Santos (Valor da Logística Integrada - VLI, 2019). No território mineiro, a infraestrutura e os serviços de transportes, voltados para o setor de commodities agrícolas, são concentrados na matriz rodoviarista, mas vem ocorrendo também o uso dos transportes intermodais na interconexão rodoferroviária.

Considerando a política de transportes em Minas Gerais, em meados da década de 1990, as empresas privadas arremataram as concessões e, a partir daí, controlam a operacionalização, a infraestrutura e os serviços de transportes. Apesar dos problemas infraestruturais e institucionais na logística de transportes, destaca-se que o Estado e os agentes privados investiram em melhoramentos da infraestrutura logística, principalmente nas áreas socioeconomicamente mais dinâmicas. No entanto, os problemas logísticos, inclusive no setor do agronegócio, existem e demandam soluções urgentes que precisam de planejamento e de recursos para custear a pavimentação e a manutenção de rodovias; a instalação de armazéns, a modernização das ferrovias, a estruturação das hidrovias, a expansão dos transportes e dos terminais intermodais, melhorias das vias de acesso aos portos, modernização da infraestrutura portuária e reformulações de legislações aduaneiras (Pereira, 2010). A logística de transportes nacional e internacional é de suma importância na viabilização dos fluxos das exportações do complexo da soja em Minas Gerais; assuntos os quais serão abordados na próxima seção. 


\section{Exportações do complexo da soja em Minas Gerais: recintos alfandegados, transportes e mercados internacionais}

Nas exportações de commodities agrícolas, a logística de transportes é estratégica na organização e na articulação espacial das atividades produtivas em um cenário de competitividade entre os mercados nacionais e internacionais. Os agentes econômicos que atuam nos mercados globais, especialmente no setor do complexo da soja, precisam conhecer as particularidades políticas, econômicas, sociais e culturais das sociedades em que pretendem inserir os seus produtos, pois precisam ser competitivos e desenvolver mecanismos para superar as restrições impostas por mercados importadores de produtos agroalimentares que sofrem variações constantes.

A volatilidade nos preços de commodities agrícolas, incluindo a soja e seus derivados, se dá pelas mudanças climáticas, redução de créditos, diminuição dos estoques, ataques de pragas/doenças às lavouras, especulações financeiras, elevação de preços de insumos agroquímicos, dentre outros. Esses fatores interferem nas variações dos preços nos mercados físicos e nos mercados futuros, influenciados pela "lei da oferta e da procura", pois se têm os momentos de alta e de baixa nos preços e isso requer conhecimentos especializados para o gerenciamento de riscos nos mercados de produtos agrícolas (Waquil et al., 2010; Conte et al., 2016).

Ao estudar a complexidade dos negócios na ciência geográfica, Mcconnell e Erickson (1986) frisam que as rápidas transformações no cenário de competitividade dos produtos levaram as empresas, especialmente as multinacionais, a desenvolver estruturas produtivas associadas ao comércio de tecnologia, de informações e de serviços gerenciais. Sendo que na internacionalização de seus negócios, as empresas gerenciam os riscos na produção, na comercialização e nos mercados especulativos, por meio do uso de serviços especializados que levam à superação de entraves relacionados a variações em taxas de câmbio, às barreiras comerciais, às políticas fiscais e ao índice inflacionário. Essas estratégias de gerenciamento são adotadas também pelas empresas que atuam no setor do agronegócio; conforme Rothstein (1983), as corporações multinacionais expandem por diversos países as suas atividades produtivas como forma de controlar, de gerenciar e de manipular o comércio global de grãos e de seus produtos processados.

Ao considerar as barreiras comerciais, Hughes (2006) destaca que essas são formuladas por meio de intervenções políticas, nas quais os estados nacionais criam e impõem os regulamentos voltados à imposição de normas ao comércio, tendo duas funções básicas; a primeira se pauta na segurança dos produtos a serem consumidos por meio de acordos internacionais institucionalizados que prezam pela qualidade e pelo respeito às leis ambientais, trabalhistas e sanitárias. A segunda caracteriza-se pelas restrições às importações, no processo de protecionismo dos mercados nacionais, sendo visível na imposição de regras, de códigos e de certificações internacionais, principalmente, nos setores da agropecuária e das indústrias. Nesse contexto, o Estado interfere na dinâmica do comércio global, uma vez que ele tem a prerrogativa institucional de atuar na manipulação da política cambial, na política de subsídios, na imposição de barreiras (tarifárias e não tarifárias) e na negociação de acordos comerciais.

Na política agrícola, as barreiras comerciais têm sido mais utilizadas pelos países, especialmente os desenvolvidos, como forma de restringir as importações de produtos; segundo Medeiros (2014) e Lima (2018), a pressão política de produtores agrícolas e de representantes das indústrias agroalimentares junto ao governo dos Estados Unidos e aos governos da União Europeia tem levado a adoção de medidas protecionistas de seus mercados, o que dificulta e/ou impede a importação de bens agroalimentares, especialmente dos países em desenvolvimento. Além da imposição de barreiras tarifárias e não tarifárias, os governos norte-americano e europeus implementam a política de subsídios agrícolas, que criam um sistema de preços artificiais, para que seus produtores 
e/ou empresas sejam competitivos nos mercados globais. Apesar de instituições supranacionais, como a Organização Mundial do Comércio - OMC, atuarem na negociação de acordos internacionais para minimizar os conflitos diplomáticos acerca do comércio internacional, por meio da redução e/ou extinção de barreiras comerciais e da liberalização dos mercados, buscando constantemente em suas rodadas de negociações a celebração de acordos multilaterais nas arenas geopolíticas.

Ao lado dos Estados Unidos e da Argentina - grandes produtores mundiais de commodities agrícolas - o Brasil tem uma participação significativa nas exportações de produtos do setor agroindustrial. A inserção de produtos agroalimentares produzidos no território brasileiro nos mercados internacionais ocorreu em função da expansão de acordos comerciais, da elevada produtividade da soja na região de cerrados com variedades que são adaptadas ao clima tropical a partir de pesquisas desenvolvidas pela Empresa Brasileira de pesquisa Agropecuária - EMBRAPA, dos incentivos fiscais, da oferta de crédito para produção comercial e da atuação de empresas multinacionais tradings companies - que controlam parte significativa da estrutura de produção, de comercialização e de exportação de produtos agroalimentares in natura e processados (Cleps Junior, 1998; Fajardo, 2011; Medeiros, 2014). Na dinâmica das exportações do complexo da soja (soja em grão, óleo e farelo de soja) que tem uma participação importante na cadeia agroalimentar brasileira, buscou-se pesquisar também a inserção de exportação de soja e derivados produzidos em Minas Gerais nos mercados internacionais.

No território mineiro, as exportações do setor do complexo da soja - considerando os fluxos acumulados no período de 1997 a 2016 - são constituídas destes produtos: soja em grãos (in natura), que representa $75,4 \%$ dos valores financeiros e $77,8 \%$ da quantidade em quilos; tortas de soja (farelo de soja) que compõem 16,6\% dos valores financeiros e 18,2\% da quantidade em peso volume; os óleos de soja representam $8,0 \%$ dos fluxos financeiros e $3,9 \%$ da quantidade em quilograma. Já os demais produtos derivados da soja, juntos, representam valores inferiores a 0,01\%. Essas informações podem ser vistas no Quadro 1.

\begin{tabular}{|l|c|c|c|c|}
\hline Produto & Valor US\$(FOB) & $\%$ & Quilograma & $\%$ \\
\hline $\begin{array}{l}\text { Soja mesmo triturada } \\
\text { (grão) }\end{array}$ & 6.380 .581 .391 & 75,4 & 17.653 .712 .162 & 77,8 \\
\hline Tortas (Farelo de soja) & 1.408 .716 .009 & 16,6 & 4.138 .274 .705 & 18,2 \\
\hline Óleo de soja & 677.588 .338 & 8,0 & 885.237 .699 & 3,9 \\
\hline Farinha de soja & 234.265 & 0,0 & 311.001 & 0,0 \\
\hline Molho de soja & 113.126 & 0,0 & 89.685 & 0,0 \\
\hline Proteínas de soja em pó & 4.043 & 0,0 & 3.134 & 0,0 \\
\hline Total & 8.467 .237 .172 & 100 & 22.677 .628 .386 & 100 \\
\hline
\end{tabular}

Quadro 1. Composição do complexo da soja por produtos exportados em Minas Gerais, fluxos acumulados no período de 1997 a 2016 (US\$\$/F.O.B; quilogramas e percentuais). Fonte: MDIC/ALICEWEB, 1997; 1998; 1999; 2000; 2001; 2002; 2003; 2004; 2005; 2006; 2007; 2008; 2009; 2010; 2011; 2012; 2013; 2014; 2015; 2016. Org. Pereira, L. A. G., 2019.

As exportações do complexo da soja em Minas Gerais mostram uma forte concentração de soja em grão, devido às estratégias de mercado desenvolvidas pelos comerciantes de soja, que são incentivados pelas políticas governamentais a vender para o exterior os produtos primários in natura, uma vez que esses são isentos de tributo. A criação da Lei Kandir - Lei Complementar nº. 87/1996 - buscou promover o estímulo às exportações com a desoneração da cobrança do Imposto sobre Circulação de Mercadorias e Serviços - ICMS, que seria compensado pela União. No complexo da soja, a partir de 
1997, a referida lei estimulou a exportação de soja em grão e acabou desestimulando as exportações de produtos processados e industrializados, como óleo e farelo de soja (Aguiar e Matsuoka, 2016). É importante destacar que as exportações de Minas Gerais estão concentradas nas commodities, principalmente das atividades mineradoras e agropecuárias.

No processo de escoamento das exportações pelos empresários com seus negócios situados no território mineiro, utilizam-se os transportes rodoviário, ferroviário e intermodal do local de produção até os recintos alfandegados, sendo esses os portos, os aeroportos e os pontos de fronteiras. Os portos estruturadores das exportações das commodities do complexo da soja são Vitória e Santos, que juntos concentraram 92,6\% das exportações em valores financeiros e $95,4 \%$ da quantidade em peso/volume. Isso ocorre devido às regiões produtoras terem a infraestrutura logística (silos, terminais e malha viária) mais articulada com esses dois recintos alfandegados, por estarem localizados mais próximos do território mineiro. Sendo o porto de Santos interligado pelas principais rodovias, que são a BR 050, BR 040 e BR 381, bem como pela ferrovia VLI que faz o uso do Terminal Integrador em Uberaba; já o porto de Vitória é interconectado pelas rodovias principais, que são BR 040 e BR 262. Além das rodovias, os exportadores usam a infraestrutura e os serviços de transporte ferroviário da VLI, que interconecta o complexo portuário de Vitória a partir dos Terminais Integradores de Araguari e de Pirapora que recebem as cargas por transporte rodoviário.

Na distribuição dos fluxos acumulados, no período de 1997 a 2016, das exportações mineiras do complexo da soja, o Porto de Vitória concentrou 48,6\% dos fluxos financeiros e $51,7 \%$ da quantidade em quilos; seguido de perto pelo Porto de Santos que recebeu $44,0 \%$ dos valores monetários e $42,8 \%$ da quantidade em peso/volume; enquanto o Porto de Paranaguá escoou 6,2\% dos fluxos financeiros e 4,5\% da quantidade em quilos; os demais recintos juntos receberam 1,2\% dos valores financeiros e 1,0\% do volume/ peso. Consequentemente, pode se afirmar que cerca de $99,9 \%$ da exportação do setor de soja é escoada para o mercado internacional pelo meio de transporte marítimo, que é adequado para a movimentação de produtos de baixo valor agregado. Os transportes rodoviários e ferroviários internacionais são utilizados para os mercados de países que fazem fronteiras terrestres, e o modal de transporte aéreo internacional é usado para o envio de pequenos volumes para os mercados internacionais, principalmente de amostras de produtos do complexo da soja. Essas informações são mostradas na Figura 5 e na Figura 6. 


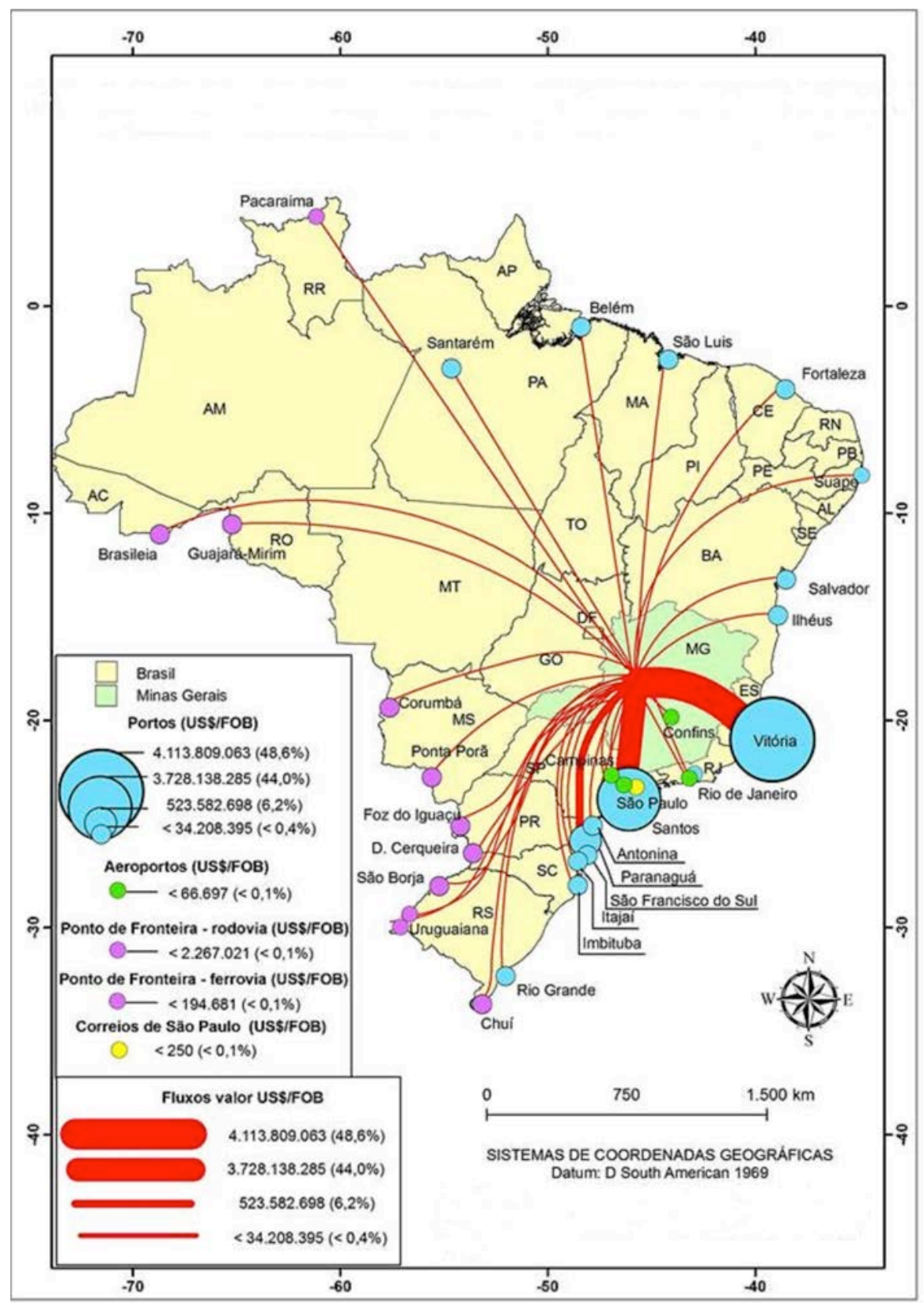

Figura 5. Exportações do setor de soja no Estado de Minas Gerais: fluxos por recintos alfandegados, no período de 1997 a 2016 (US\$\$FOB). Fonte: MDIC/ALICEWEB, 1997; 1998; 1999; 2000; 2001; 2002; 2003; 2004; 2005; 2006; 2007; 2008; 2009; 2010; 2011; 2012; 2013; 2014; 2015; 2016. Org. Pereira, L. A. G., 2017. 


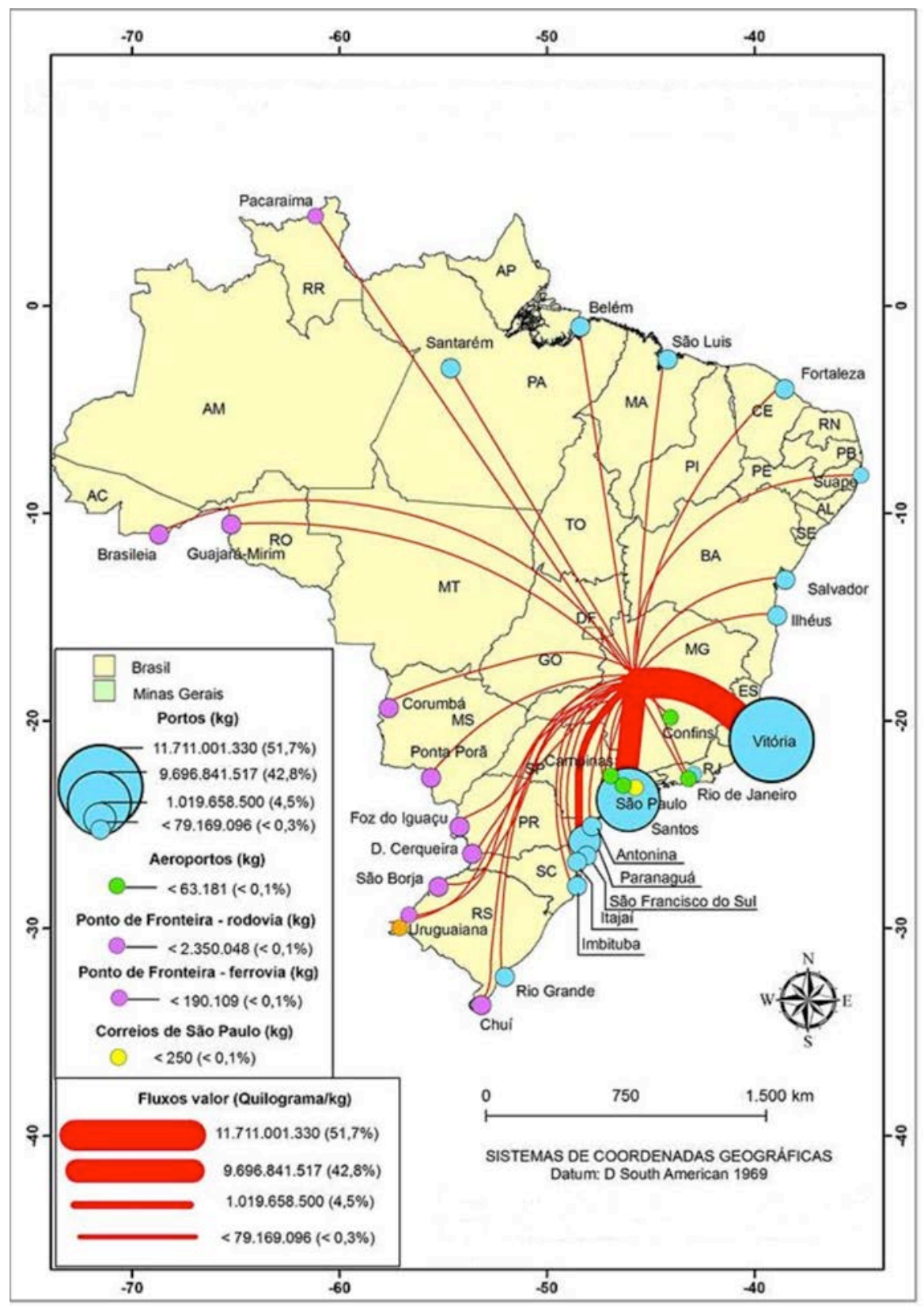

Figura 6. Exportações do setor de soja no Estado de Minas Gerais: fluxos por recintos alfandegados, no período de 1997 a 2016 (kg). Fonte: MDIC/ALICEWEB, 1997; 1998; 1999; 2000; 2001; 2002; 2003; 2004; 2005; 2006; 2007; 2008; 2009; 2010; 2011; 2012; 2013; 2014; 2015; 2016. Org. Pereira, L. A. G., 2017.

No cenário das exportações do agronegócio, segundo Huertas (2016), as tradings têm o papel de estruturar o transporte de cargas no modal rodoviário e usam táticas de rebaixar os valores dos preços dos fretes, criando reserva de mercado ao impor a carteira de frotistas por meio de comissões no pagamento extra da tonelada transportada. Elas controlam os circuitos espaciais por uma logística privilegiada, que adota em seu escopo estratégia organizacional e territorial a partir de pesquisas de mercados, que levam à localização ótima das unidades processadoras e armazenadoras, à redução de períodos sazonais das safras, ao controle na cotação dos fretes por quilômetro rodado, à celebração de contrato com transportadores como forma de reação às variações de preços e à atuação de agentes que informam acerca da 
programação de navios nos portos. Conforme dados já apresentados, grande parte das exportações do complexo da soja faz uso de infraestruturas portuárias.

Em Minas Gerais, as tradings companies concentram as exportações do complexo da soja pelo fato de estarem integradas às cadeias logísticas de distribuição dos produtos nos mercados globais, incorporando uma rede de fornecedores e de prestadores de serviços. Os fluxos das exportações do complexo da soja, ao saírem dos recintos alfandegados localizados no território brasileiro, são direcionados para os mercados internacionais, que foram organizados em blocos econômicos regionais: Cooperação Econômica da Ásia e do Pacífico (APEC), União Europeia (UE), Associação Sul-Asiática para Cooperação Regional (SAARC), União Aduaneira da África Austral (SACU), Mercado Comum do Sul (MERCOSUL 5) e Tratado Norte-Americano de Livre Comércio (NAFTA). Com relação às exportações do complexo da soja, considerando os fluxos financeiros e em quilogramas acumulados, no período de 1997 a 2016, destacou-se a APEC, que recebeu $61,9 \%$ dos valores financeiros e $55,9 \%$ da quantidade em quilos, enquanto a União Europeia comprou 32,9\% dos valores em dinheiro e 40,4\% do peso/ volume; juntos, os demais blocos e países, receberam 7,4\% dos fluxos financeiros e $5,5 \%$ da quantidade em quilograma. Essas informações são mostradas na Figura 7.

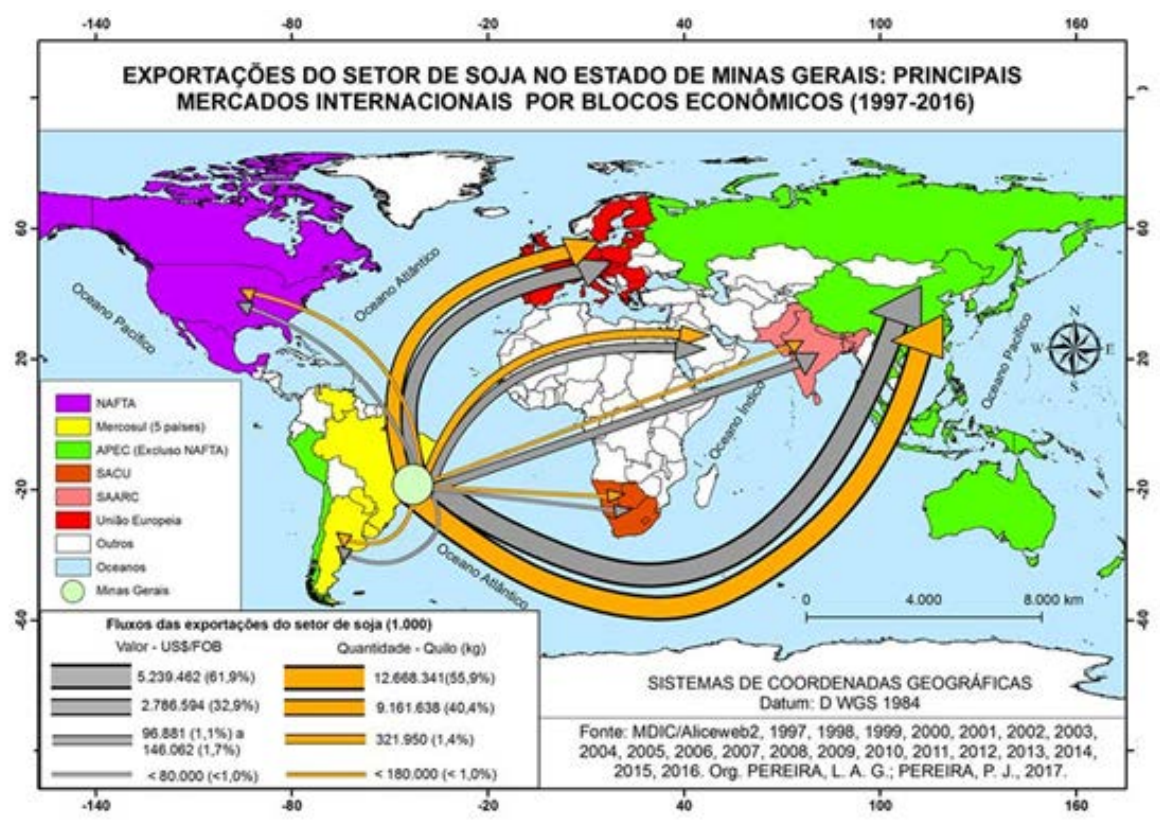

Figura 7. Exportações do setor de soja no Estado de Minas Gerais: principais mercados internacionais por blocos econômicos (1997-2016). Fonte: MDIC/ALICEWEB, 1997; 1998; 1999; 2000; 2001; 2002; 2003; 2004; 2005; 2006; 2007; 2008; 2009; 2010; 2011; 2012; 2013; 2014; 2015; 2016. Org. Pereira, L. A. G., 2017.

O processo de organização das exportações por blocos econômicos mostra um cenário de competitividade das empresas do complexo da soja localizadas em Minas Gerais nos mercados da APEC (excluso o NAFTA), que é o principal mercado de destino das exportações mineiras de soja e derivados, em função do crescimento da demanda chinesa por commodities agrícolas. O segundo maior mercado de destino da exportação de Minas Gerais é o bloco da União Europeia, e o mercado do Oriente Médio é o terceiro destino mais importante. Enquanto os demais blocos e/ou países têm uma baixa participação nas importações de soja e derivados das empresas localizadas em Minas Gerais. Destaca-se a baixa penetração de produtos do complexo da soja nos mercados do bloco do NAFTA que representam um valor menor que 1,0\%; isso é decorrente da forte presença dos Estados Unidos na produção e na exportação de produtos agroalimentares. 


\section{Considerações finais}

As redes geográficas têm a finalidade de promover as articulações das atividades humanas por meio das interações espaciais entre a infraestrutura e os fluxos de pessoas, bens, serviços e informações no espaço geográfico. Na estrutura política, econômica e social das redes geográficas, a logística é abordada por meio de diálogos da ciência geográfica com outras áreas do conhecimento, principalmente a administração. Os geógrafos pesquisam e discutem acerca da logística por meio dos serviços que propiciam o planejamento, a gestão e controle dos fluxos de mercadorias em uma estrutura espacial que incorpora a origem e o destino no atendimento das demandas dos consumidores.

A logística agroindustrial é constituída por um conjunto de serviços de transportes, de armazenagem e de informações que são utilizados pelos agentes econômicos atuantes no setor do agronegócio para produzir, para comercializar e distribuir bens agroalimentares in natura e processados nos mercados nacionais e internacionais. De modo que o transporte é a parte operacional da logística que demanda infraestrutura e serviços para escoar, fazer transbordos e armazenar produtos na cadeia de suprimentos e na cadeia de consumo.

O processo de comercialização de produtos agroalimentares levou os exportadores a desenvolver as estratégias de negócios para inserção da produção do complexo da soja nos mercados globais, buscando adaptar seus produtos às exigências dos consumidores e conhecer os canais de distribuição das exportações em um cenário permeado por concorrência, por barreiras comerciais e por subsídios que são estabelecidos pelas economias desenvolvidas em detrimento das economias em desenvolvimento.

Na estrutura da política agrícola brasileira, a partir das décadas de 1970/1980, os agentes econômicos intensificaram a produção de soja e derivados no Estado de Minas Gerais, principalmente nas mesorregiões do Triângulo Mineiro, Alto Paranaíba, Sul de Minas, Noroeste de Minas, Centro-Oeste de Minas, Central e Norte de Minas. Isso ocorreu em razão dos incentivos fiscais e das linhas de créditos que favoreceram a expansão do capital privado por meio da atuação de produtores rurais e de instalação de empresas processadoras de grãos, dentre as quais se destacam as multinacionais. Na exportação de produtos do complexo da soja, a soja in natura (grão) representou $75,4 \%$ dos valores financeiros e $77,8 \%$ da quantidade quilograma. Esses dados mostram que a política de exportações do complexo da soja prioriza os produtos não processados, por isso é importante os governos brasileiro e mineiro desenvolverem medidas de incentivo às exportações de produtos processados, com agregação de valor a esses.

O escoamento das exportações de produtos do complexo da soja das unidades produtoras/processadoras até os recintos alfandegados se dá na maior parte pelo transporte rodoviário, enquanto o transporte intermodal rodoferroviário expandiu-se, a partir de 2009, com a criação dos terminais integradores de transportes, que são Pirapora, Araguari e Uberaba. Nesse contexto, os recintos alfandegados de Vitória e Santos, juntos, concentraram $92,6 \%$ dos valores financeiros e 94,5 da quantidade em quilograma das cargas do complexo da soja. Essa concentração ocorreu pelo fato de os corredores de transportes, sejam eles rodoviário e/ou intermodal (rodoferroviário), interligarem os portos de Vitória e Santos que são também especializados na movimentação de produtos agrícolas. No transporte internacional, o marítimo concentrou aproximadamente 99,9\% dos produtos do complexo da soja, que é um modal indicado para o transporte de produtos de baixo valor agregado, como é o caso dos produtos agrícolas. Além disso, a modalidade marítima é uma alternativa de transportes mais viável na movimentação intercontinental desse perfil de mercadoria. 
Diante dos problemas logísticos, os agentes econômicos, localizados em Minas Gerais, são competitivos no cenário internacional e escolheram a infraestrutura e os serviços de transportes mais adequados para o escoamento da produção do complexo da soja exportada. No entanto, torna-se necessário que os governos brasileiro e mineiro, e os empresários desenvolvam estratégias de investimentos para melhoria da infraestrutura de transportes e de armazenagem, busquem agregar valor aos produtos exportados do setor agroindustrial, atendam os requisitos dos consumidores internacionais e negociem acordos internacionais para expansão das exportações.

AGRADECIMENTOS: À Fundação de Apoio à Pesquisa do Estado de Minas Gerais FAPEMIG, pelo financiamento do projeto, ao qual encontra-se vinculada esta pesquisa. 


\section{Q Bibliografia}

" Aguiar, D. R. D., y Matsuoka, B. P. (2016). Mudanças na pauta de exportações e a primarização do complexo soja. Revisa de Política Agrícola, 25 (1), 20-34.

"Ballou, R. H. (1993). Logística empresarial: transportes, administração de materiais e distribuição física. São Paulo: Atlas.

» Brasil, Instituto Brasileiro de Geografia e Estatística - IBGE. (1955). Anuário Estatístico do Brasil - AEB. Rio de Janeiro: IBGE.

» Brasil, Instituto Brasileiro de Geografia e Estatística - IBGE. (1963). Anuário Estatístico do Brasil - AEB. Rio de Janeiro: IBGE.

» Brasil, Instituto Brasileiro de Geografia e Estatística - IBGE. (1971). Anuário Estatístico do Brasil - AEB. Rio de Janeiro: IBGE.

» Brasil, Instituto Brasileiro de Geografia e Estatística - IBGE. (1981). Anuário Estatístico do Brasil - AEB. Rio de Janeiro: IBGE.

» Brasil, Instituto Brasileiro de Geografia e Estatística - IBGE. (1993). Anuário Estatístico do Brasil - AEB. Rio de Janeiro: IBGE.

》 Brasil, Instituto Brasileiro de Geografia e Estatística - IBGE. (2000). Anuário Estatístico do Brasil - AEB. Rio de Janeiro: IBGE.

» Brasil, Instituto Brasileiro de Geografia e Estatística - IBGE. (2010). Anuário Estatístico do Brasil - AEB. Rio de Janeiro: IBGE.

»Brasil, Instituto Brasileiro de Geografia e Estatística - IBGE. (2017). Anuário Estatístico do Brasil - AEB. Rio de Janeiro: IBGE.

» Brasil, Plano Nacional de Logística e transportes - PNLT. (2010). Bases geográficas. Brasília: Ministério dos Transportes.

" Brasil. (2009). Lei Federal n 6.759 de os de fevereiro de 2009. Regulamenta a administração das atividades aduaneiras, e a fiscalização, o controle e a tributação das operações de comércio exterior. Brasília.

" Caixeta-Filho, J. V. (2001). Introdução: a competitividade do transporte no agribusiness brasileiro. En Caixeita-Filho, J. V.; Gameiro, A. H. (Org.). Transporte e logística em sistemas agroindustriais. São Paulo: Atlas.

»Caixeta-Filho, J. V. (2010). Logística para a agricultura brasileira. Revista Brasileira de Comércio Exterior, 103, 18-30.

»Castillo, R. (2004). Transporte e logística de granéis sólidos agrícolas: componentes estruturais do novo sistema de movimentos do território brasileiro. Investigaciones Geográficas, [S.I.], 55, 79-96.

"Castillo, R. (2005). Exportar alimentos é a saída para o Brasil?: O caso do complexo da soja. In: Albuquerque, E. S. (Org.). Que país é esse? Pensando o Brasil contemporâneo. São Paulo: Globo.

》 Castillo, R. (2007). Agronegócio e Logística em Áreas de Cerrado: expressão da agricultura científica globalizada. Revista da ANPEGE, 03, 33- 43.

" Castillo, R.; y Frederico, S. (2010). Dinâmica regional e globalização: espaços competitivos agrícolas no território brasileiro: Mercator, 9 [18], 16-26.

»Cleps Junior, J. (1998). Dinâmica e estratégias do setor agroindustrial no cerrado: o 
caso do Triângulo Mineiro. Tese Doutorado em Organização do Espaço, Instituto de Geociências e Ciências Exatas, UNESP, Rio Claro.

»Conte, B. P.; Coronel, D. A.; y Amorim, A. I. (2016). Análise da volatilidade do complexo brasileiro de soja em relação ao mundo. Revista de Política Agrícola, 25 [2], 26-38.

» CORRÊA, R. L. (2006). Interações espaciais. In: Castro, I. E.; GOMES, P. C. C.; CORRÊA, R. L. (Org.). Explorações geográficas. Rio de Janeiro: Bertrand Brasil.

" David, P., y Stewart, R. (2010). Logística internacional. São Paulo: Cengage Learning.

» Fajardo, S. (2011). A ação territorial corporativa no espaço rural. En Videira, S. L.; Costa, P. A.; Fajardo, S. Geografia Econômica: (re)leituras contemporâneas. Rio de Janeiro: Letra Capital.

»Frederico, S. (2010). Desvendando o agronegócio: financiamento agrícola e o papel estratégico do sistema de armazenamento de grãos. GEOUSP, 27, 47-61.

"Frederico, S. (2013). Modernização da agricultura e uso do território: a dialética entre o novo e o velho, o interno e o externo, o mercado e o estado em áreas de cerrado. GEOUSP, 34, 46-61.

» Frederico, S. (2014). Circuito espacial produtivo do café e o jogo de escalas. Mercator, 13 (01), 37-48.

" Garcia, J. R., y Andrade, D. C. (2007). Panorama geral da industrialização de Minas Gerais (1970-2000). Leituras de Economia Política, 12, 155-182.

» Hoyle, B. y Knowles, R. (2001). Modern Transport Geography. 2. ed. ChichesterUK: John Wiley \& Sons Ltd.

» Huertas, D. M. (2015). Dinâmicas territoriais do transporte rodoviário de carga no polígono nodal do agronegócio sulista. Geosul, Florianópolis, 29 (58), 161184 .

" Huertas, D. (2014). Dinâmicas territoriais dos eixos nodais que comandam a logística rodoviária do agronegócio no Centro-Oeste brasileiro. Ateliê Geográfico, 8 (2), 38-64.

»Hughes, A. (2006). Geographies of exchange and circulation: transnational trade and governance. Progress in Human Geography, 30 (5), 635-643.

»Instituto Brasileiro de Geografia e Estatística - IBGE. (2018). Divisão territorial Bases cartográficas. Brasília: IBGE. Disponível em: <https://mapas.ibge.gov.br/ bases-e-referenciais.html>. Acesso em: 22 jan. 2018.

»Instituto Brasileiro de Geografia e Estatística - IBGE. (2010). Censo 2010. Brasília: IBGE. Disponível em: <https://censo201o.ibge.gov.br/ >. Acesso em: 22 nov. 2017.

»Instituto Brasileiro de Geografia e Estatística - IBGE. (2017). Minas Gerais IBGE - Cidades. Brasília: IBGE. Disponível em: <https://cidades.ibge.gov.br/ brasil/mg/panorama >. Acesso em: 22 nov. 2017.

"Instituto Brasileiro de Geografia e Estatística - IBGE. (2019). Sidra - Produção agrícola municipal. Brasília: IBGE. Disponível em: <https://sidra.ibge.gov.br/ Tabela/1612>. Acesso em: os jun. 2019.

» Leal, M. N. y França, V. L. (2011). A. Modernização e reestruturação da produção agrícola e a organização do espaço agrário brasileiro. Revista Geográfica de América Central, Número Especial EGAL 2011, 1-15. 
»Lima, T. (2018). O protecionismo agrícola nos Estados Unidos: resiliência e economia política dos complexos agroindustriais. São Paulo: Editora UNESP.

»Lourenço, J. C. (2009). Logística Agroindustrial: desafios para o Brasil na primeira década do século XXI. Monografia Graduação em Administração, Centro de Ciênciais Humanas, Sociais e Agrárias, Universidade Federal da Paraíba, Bananeiras.

»Malagolli, G. A. y Ascanio, E. (2007). A importância da armazenagem para a logística agroindustrial - o caso do amendoim brasileiro. Interface Tecnológica, 4 (1), 73-83.

» Mcconnell, J. E. y Erickson, R. A. (1986). Geobusiness: An International Perspective for Geographers. Journal of Geography, 85 (3), 98-105.

» Medeiros, M. C. (2014). A Geografia do mercado mundial de produtos agroalimentares e o papel do Brasil. Raega, 31, 260 - 279.

» Ministério do Desenvolvimento Indústria e Comércio Exterior - MDIC/ ALICEWEB2. (1997; 1998; 1999; 2000; 2001; 2002; 2003; 2004; 2005; 2006; 2007; 2008; 2009; 2010; 2011; 2012; 2013; 2014; 2015; 2016). Exportação/ Estados - Minas Gerais. Brasília: MDIC. Disponível em: <http://aliceweb2. mdic.gov.br/>. Acesso em: 10 maio 2017.

» Ministério dos Transportes, Portos e Aviação Civil - MTPA. (2017). Corredores logísticos estratégicos: complexo de soja e milho. Brasília: MTPA.

"Novaes, A. G.(2001). Logística e gerenciamento da cadeia de distribuição: estratégia, operação e avaliação. Rio de Janeiro: Elsevier.

»Pereira, L. A. G. (2015). Logística de transportes e comercio internacional: os fluxos das exportações e das importações de mercadorias no norte de Minas Gerais. Tese Doutorado em Geografia, Instituto de Geografia, Universidade Federal de Uberlândia, Uberlândia.

»Pereira, L. A. G., y Ferreira, W. Redes de transportes e comércio internacional: os fluxos das exportações do setor siderúrgico-metalúrgico no norte de Minas Gerais. RA'EGA, 29, 64-91.

»Pereira, L. A. G. (2010). Planejamento e desenvolvimento: Logística de transportes e exportações na mesorregião norte de Minas Gerais. Dissertação mestrado em Desenvolvimento Social, Programa de Pós-Graduação em Desenvolvimento Social, UNIMONTES, Montes Claros.

"Pereira, C. S., y Hespanhol, A. N. (2015). Região e regionalizações no Estado de Minas Gerais e suas vinculações com as políticas públicas. Revista Formação, 1 (22), 42-70.

»Pontes, H. L. J.; Carmo, B. B. T.; y Porto, A. J. V. (2009). Problemas logísticos na exportação brasileira da soja em grão. Sistemas \& Gestão, 4 (2), 155-181.

» Rothstein, M. (1983). Multinationals in the Grain Trade, 1850-1914. Business and Economic History, 12, 85-93.

"Silva, K. A. O. (2007). Padrão de especialização e competitividade das exportações de Minas Gerais no período recente. Dissertação Mestrado em Economia, Pósgraduação em Economia, Universidade Federal de Uberlândia, Uberlândia.

» Silveira, M. R. (2011). Geografia da circulação, transportes e logística: construção epistemológica e perspectivas. En Silveira, Marcio Rogério. (Org.). Circulação, transportes e logística: diferentes perspectivas. São Paulo: Outras Expressões.

» Valor da Logística Integrada - VLI. (2019). Corredores logísticos: terminais. 
Disponível em: <http://www.vli-logistica.com.br/conheca-a-vli/corredoreslogisticos >. Acesso em: 10 fev. 2019.

"Waquil, P. D.; Miele, M.; y Schultz, G. (2010). Mercados e comercialização de produtos agrícolas. Porto Alegre: Editora da UFRGS.

\section{Patrick Pereira de Jesus / patrickpereiradejesus@gmail.com}

Graduado em Geografia pela Universidade Estadual de Montes Claros (UNIMONTES). Atualmente é Acadêmico do Programa de Pós-Graduação em Geografia da Universidade Estadual de Montes Claros (UNIMONTES).

\section{Luiz Andrei Gonçalves Pereira / luizandreigoncalves@yahoo.com.br}

Graduado em Geografia pela Universidade Estadual de Montes Claros (UNIMONTES), Mestre em Desenvolvimento Social pela Universidade Estadual de Montes Claros (UNIMONTES), Doutor em Geografia pela Universidade Federal de Uberlândia (UFU). Atualmente é Docente do Departamento de Geociências e do Programa de PósGraduação em Geografia da Universidade Estadual de Montes Claros (UNIMONTES). 